\title{
Discussion and Thinking on Online Teaching Under the Background of "Suspended Class and On-Going Learning"
}

\author{
Ning shen ${ }^{1, *}$ \\ ${ }^{1}$ School of Mathematics and Computer Science, Jianghan University, Wuhan, Hubei 430056, China \\ *Corresponding author. Email: 274912440@qq.com
}

\begin{abstract}
Topic about suspended class and on-going learning has been discussed heatedly. How can we take advantage of online teaching to a larger extent while fighting against the epidemic? This paper analyses the advantages and disadvantages of online teaching under the background of "suspended class and on-going learning", and proposes strategies to allow the online teaching to work well.
\end{abstract}

Keywords: online teaching, traditional teaching, suspended class and on-going learning, online learning

\section{INTRODUCTION}

At the beginning of 2020, an unprecedented epidemic has swept across the whole country with a great impact on the lives of people all over the country. In order to win the battle against COVID-19, the extended holiday policy has been implemented across the country. In February, the Ministry of Education issued an initiative to "suspended class and on-going learning "[1], which has become the mainstream of stay-at-home students' holiday life in the face of "extended holidays". Nearly 300 million people, including teachers and students, participated in the largest educational experiment in history. Teachers become web celebrities and the place of class is changed from school to home. It's a new experience for both teachers and students. The debate on online education sweeping across the country is being discussed heatedly [2].

\section{CURRENT SITUATION OF ONLINE TEACHING}

Because it is an unprecedented educational revolution, everybody is groping forward. For teachers, there is no unified teaching model. For students, they must get accustomed to the teaching model with free location and no supervision.

In terms of teachers, the most important problems are which teaching methods to use and how to attract students' attention.

The most common teaching methods are summarized as follows:

The imparting of knowledge can be divided into two categories:

1. Live broadcast teaching, such as QQ's classroom live, Ding Talk's live broadcast and Tencent's video conference 2. Sharing excellent instructional videos from online educational web sites.
Teachers' interaction with students, such as the sharing of materials, assignment and correction of homework, can also be divided into two categories

1. Relying on online teaching course platforms and utilizing the built-in functions of the platform, such as assigning homework and taking exams on the Super Star platform.

2. Directly utilizing instant messaging network tools to contact and interact with students, such as Ding Talk, QQ and so on.

In online teaching, how teachers attract students' attention and stimulate students' enthusiasm is very vital. The teacher can neither see each student nor see the whole class so that the teacher can't directly manage the class. Whether students can study well or not depends on their self-control and parental supervision for there are not teachers' monitoring. Therefore, in order to attract the attention of students, teachers rack their brains. Some are as good as web celebrities. They get well prepared, and have great personal charm to attract students, becoming very popular among students on the network. Others are not ready, and cannot cope with online teaching calmly. Those have to come up with some strange ideas, such as playing erhu during class intervals, or tell jokes in class to draw students' attention, but with little effect.

In terms of students, learning environment, their own learning attitude and their parents' supervision are the primary factors causing the difference in learning effect. In many underdeveloped areas, students cannot access the fluent Internet and electronics, so online teaching cannot be carried out. For those who have access to the Internet and available electronics, they study at home either on their own or under the supervision of their parents. If students have self-control and effective supervision, they can get good effects and save time on the way to school. However, due to lack of self-control and parental supervision, some children who study at home without the company of teachers and classmates forming a good learning environment lose themselves when faced with 
free network. They become addicted to the network, which ends up with irregular lifestyle, and poor learning effects.

\section{ADVANTAGES AND DISADVANTAGES OF ONLINE TEACHING COMPARED WITH TRADITIONAL TEACHING}

Mohamed Ally has pointed out that learning is influenced more by the content and instructional strategy in the learning materials than by the type of technology used to deliver instruction [3]. Before the epidemic, online teaching had just been a complement of traditional teaching. In the course, University Computer Basis, which is taught in the way of mixed online and traditional teaching in our university, the interaction and communication between teachers and students in traditional class plays a significant role in the study as well, although online teaching takes up a larger proportion. Nevertheless, due to the epidemic, traditional classroom teaching has been completely replaced by online teaching. Does it mean that with the development of technology, traditional classroom teaching will be gradually replaced by online teaching or the school will disappear? Let's compare the advantages and disadvantages of online teaching and traditional teaching.

\subsection{Advantages of online teaching}

\subsubsection{Teachers can save time on teaching management and devote themselves to preparing lessons}

In traditional classroom, teachers have to participate in the management of students, which requires a lot of time and energy. As it also takes time to correct homework, the preparation time for teachers is limited. Now, the online teaching enables teachers to save a large proportion of time to manage students. Several classes can be merged into one class, which also saves the time to give repeated lectures. In addition, homework assignment with the help of network platform greatly promotes efficiency of homework correction. Consequently, teachers can have plenty of time to prepare lessons. They can learn from others' excellent teaching cases on the Internet, and improve their professional abilities.

\subsubsection{Online teaching removes the barrier for time and space}

During the epidemic, students were unable to return to school. With the help of online teaching, the study has not been delayed. The time of online learning is very flexible in contrast to the traditional classroom learning. If you cannot go to school one day, of course, you will miss the class. But during the period of online learning, even if students miss the live broadcast, they can watch the replay at any time repeatedly.

You can attend class no matter where you are, just needing a computer, an IPAD, or a mobile phone, even if you are away on business. But in traditional classroom learning, you have to go to school. Sometimes it's even more difficult when the weather is not nice.

\subsubsection{Online teaching promotes the integration of educational network resources}

We can make good use of all kinds of high-quality educational resources on the Internet. Teachers can recommend the best to students after screening. The online teaching of this year has gathered all the high-quality resources of the whole province and even the whole country, which is good reference for front-line teachers. During the epidemic period, our school organized teachers to make high-quality online courses, and refined the traditional classroom teaching contents to form rich and comprehensive teaching resources with vivid graphics, pictures, audio and video, so as to improve students' interest in learning. It is especially beneficial to the students with strong self-control and excellent learning ability.

\subsubsection{Online teaching can solve the problem of unbalanced distribution of educational resources to some extent.}

There are many backward and remote areas in China where the educational resources are seriously deficient. The schools of areas with developed educational resources which have rich cultural accumulation and abundant high-quality educational resources can Share them with students in backward and remote areas through network technology. Moreover, educational resources in the same area also vary from school to school. If the school is not very good, students there can gain access to famous teacher's courses through the Internet, thereby achieving good academic performance.

\subsubsection{Online teaching makes it possible to teach students in accordance with their aptitude to some extent.}

All classroom live broadcasts can be replayed. If students have some problems in their study, they can watch live broadcasts again and again until they understand. Students can make learning plans according to their individual needs, and choose the most optimal learning mode. There are so many online courses for students to choose that everybody can find the most suitable ones. 


\subsection{Disadvantages of online teaching}

However, everything has two sides, and online teaching also has many shortcomings

\subsubsection{Online teaching is greatly influenced by terminal equipment and network.}

Students in remote areas have difficulty in accessing computers and mobile phones with fluent network. The lack of technology and hardware make it impossible for them to take regular online classes so that the learning effect is greatly reduced. In addition, some students do not have a quiet learning atmosphere, and online teaching will also be affected.

\subsubsection{Students suffer from poor eyesight}

Due to the epidemic, children seldom go out and have to rely on Internet devices for online learning at home. Children tend to spend the whole day sitting in front of electronic screens, which leads to excessive use of their eyes and poor eyesight. Previously parents didn't allow children to use mobile phones, and computers were also strictly controlled. At present, children must use mobile phones and computers in online learning so that it is not easy for parents to supervise. Many children spend such a long time using mobile phones and computers each day that their eyesight becomes poor.

\subsubsection{Without strong supervision, online learning tends to develop bad study habits}

Young children are not mature enough to resist the temptation of mobile phones, and computers. Under the severe situation of the epidemic, parents are not allowed to go out to work, so they can supervise their children' study at home, which leads to good study effect. When the epidemic has been controlled, parents return to work and students stay at home alone. In this case, they may secretly play games and watch movies on the Internet while attending class. They do not develop good study habits, thereby becoming addicted to the Internet.

\subsubsection{There is not enough interaction and communication between teachers and students}

In online teaching, the teacher cannot see the state of the students' study and cannot give feedback on the study effect instantly. In the process of teaching, teachers need to know whether students can keep up with the pace of teaching at any time [4]. In the traditional teaching process, the teacher will grasp the state of students' study effect according to the students' expressions or questions. Teachers can help students keep up by reducing the teaching speed, repeatedly explaining, asking questions. However, in the process of online teaching, teachers are limited by the platform and cannot see every student in the live class. On the other hand, during the live broadcast, teachers cannot ask a student questions by name in order to know his or her state of mind. Only students can apply and connect the teacher if they have questions. Only one student can be connected at a time, so group communication cannot be realized. In this way, the interaction and communication not only between teachers and students but also between students are so limited that the teacher cannot adjust the pace of teaching in accordance with students.

\subsubsection{Teachers can't manage the classroom so that some students can't discipline themselves}

In traditional classroom, if a student gets distracted from class, the teacher will remind him in time. Nevertheless, in the online teaching, the teacher cannot find students' behaviors during the class such as doing other things and leaving their seats and so on. Due to the lack of adequate supervision, it is hard for a large proportion of students to conduct online learning.

\subsubsection{The teacher cannot stimulate students' enthusiasm s from the screen,}

Separated by an electronic screen, teachers can only impart knowledge to students, but they cannot convey the enthusiasm [5]. Teaching process is a process of teaching and learning. In traditional teaching process, the more enthusiastic students are, the more teachers will be motivated. Likewise, the more enthusiastic the teacher is, the more students will be affected. However, teachers can just imagine the feedback $\mathrm{f}$ students when lecturing on the screen during online teaching. It is difficult to stimulate the enthusiasm of teaching, and students may get distracted more easily.

\section{CONCLUSION}

\subsection{Online teaching cannot replace the traditional classroom in school}

No matter how advanced the science and technology is, face-to-face teaching and schools will not disappear. Although online education can complement traditional classroom at school, the education of school is not only imparting knowledge to students but also developing students' communication ability and receiving moral 
education. It is clear that traditional classroom teaching is irreplaceable.

\subsection{Online learning cannot completely solve the problem of educational inequality}

Online teaching solves the problem that high-quality resources are shared, and actually it cannot replace schools. A school is a place for education, which imparts not only knowledge but also emotions, attitudes and values. Students in elite schools are influenced by the school culture and spirit. When we look around the world, we will find that elite schools always are scarce resources. It is impossible to replace school choice through online education.

\subsection{Online learning needs to pay attention to protect students' eyesight}

As online learning may result in poor eyesight, what can students do to protect their eyesight? Try to maximize the screen effect, not too close to the computer. Close eyes and rest for about 30 to 45 minutes, or relax eyes in other ways, such as doing eye exercises. Try not to study in bed or on the sofa, or in the wrong posture, which makes students fail to concentrate on studies. They need to adjust their mind and body to focus on their studies

\subsection{Active learning is fundamentally dependent on students themselves}

Online education has great freedom, which provides students with the possibility of active learning. At the same time, because the teacher is not teaching with the students in class but through video online, it also tests the students' consciousness more. However, no matter which way teachers teach in, students can take the initiative to learn by themselves. If students don't want to learn, teachers can't force you even if they provide good learning resources. The Internet only provides a means and an opportunity, and the solution to the problem lies in the students' three views, including their perception, values and attitudes.

\subsection{How can online teaching attract students' attention}

The problem should not be confined to online teaching, and it is also vital to traditional classroom teaching. No matter how you teach, what really attracts students is the unique personality of the teacher and the best content, regardless of whether it is taught in a traditional classroom or online. First of all, teachers should use their personal charm to attract students to attend the class. And then, teachers should firmly grasp the attention of students with excellent teaching content. As a matter of fact, some teachers tell jokes or even play up to students in class in order to attract students. I think it undesirable to do these things. A teacher's inner power is the primary factor to appeal to students. Teachers should strive to improve their teaching ability and draw students with the charm of knowledge.

\section{REFERENCES}

[1] Ministry of Education of the People's Republic of China, Notice of the Ministry of Education on the postponement of the spring Semester 2020[EB/OL].[2020-01-29].http://www.moe.gov.cn/jyb_x wfb/gzdt_gzdt/s5987/202001/t20200127_416672.html.

[2] Hu xiaoyong, How to do online teaching under the epidemic? [J], Today's education, 2020(3):14-17.

[3] Ally M. Foundations of educational theory for online Calgary $[\mathrm{M}] / /$ Anderson $\mathrm{T}$, the Theory and Practice of Online Learning: Athabasca University, 2005:3-31.

[4] Wang zhijun, The essence and related concepts of "teaching interaction" in distance education [J], Research on audio-visual Education, 2016(04)

[5] Xiao jiao, Research on the Interactivity of teaching Media in distance Education [J], Chinese Adult Education, 2018(2):105-108 